This item was submitted to Loughborough's Research Repository by the author.

Items in Figshare are protected by copyright, with all rights reserved, unless otherwise indicated.

\title{
Facile multicomponent polymerizations toward unconventional luminescent polymers with readily openable small heterocycles
}

PLEASE CITE THE PUBLISHED VERSION

https://doi.org/10.1021/jacs.8b01991

\section{PUBLISHER}

(C) American Chemical Society

\section{VERSION}

AM (Accepted Manuscript)

\section{PUBLISHER STATEMENT}

This work is made available according to the conditions of the Creative Commons Attribution-NonCommercialNoDerivatives 4.0 International (CC BY-NC-ND 4.0) licence. Full details of this licence are available at: https://creativecommons.org/licenses/by-nc-nd/4.0/

\section{LICENCE}

CC BY-NC-ND 4.0

\section{REPOSITORY RECORD}

Han, Ting, Haiqin Deng, Zijie Qui, Zheng Zhao, Haoke Zhang, Hang Zou, Nelson L.C. Leung, et al.. 2018. "Facile Multicomponent Polymerizations Toward Unconventional Luminescent Polymers with Readily Openable Small Heterocycles". Loughborough University. https://hdl.handle.net/2134/32941. 


\title{
Facile Multicomponent Polymerizations toward Unconventional Luminescent Polymers with Readily Openable Small Heterocy- cles
}

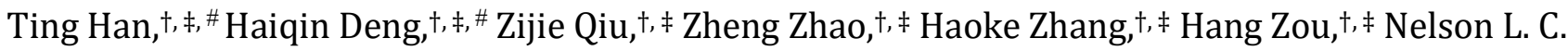 \\ Leung, ${ }^{\dagger} \neq$ Guogang Shan,,$+\neq$ Mark R. J. Elsegood,, Jacky W. Y. Lam, ${ }^{*,+, \neq ~ a n d ~ B e n ~ Z h o n g ~ T a n g *, ~}, \neq, \S$ \\ †Department of Chemistry, Hong Kong Branch of Chinese National Engineering Research Center for Tissue Restoration \\ and Reconstruction, Institute for Advanced Study, Division of Biomedical Engineering and Division of Life Science, The \\ Hong Kong University of Science and Technology, Clear Water Bay, Kowloon, Hong Kong, China \\ ‡HKUST-Shenzhen Research Institute, No. 9 Yuexing 1st RD, South Area, Hi-tech Park, Nanshan, Shenzhen 518057, \\ China \\ $\S$ China NSFC Center for Luminescence from Molecular Aggregates, SCUT-HKUST Joint Research Institute, State Key \\ Laboratory of Luminescent Materials and Devices, South China University of Technology, Guangzhou 510640, China \\ ॠChemistry Department, Loughborough University, Loughborough, Leicestershire, LE11 3TU, UK \\ Supporting Information
}

\begin{abstract}
Heterocyclic polymers have gained enormous attention for their unique functionalities and wide applications. In contrast with the well-studied polymer systems with five- or six-membered heterocycles, functional polymers with readily openable small-ring heterocycles have rarely been explored due to their large synthetic difficulty. Herein, a facile one-pot multicomponent polymerization to such polymers is developed. A series of functional polymers with multisubstituted and heteroatom-rich azetidine frameworks are efficiently generated at room temperature in high atom economy from handy monomers. The fourmembered azetidine rings in the polymer skeletons can be easily transformed into amide and amidine moieties via a fast and efficient acid-mediated ring-opening reaction, producing brand-new polymeric materials with distinctive properties. All the asprepared azetidine-containing polymers exhibit intrinsic visible luminescence in the solid state under long-wavelength UV irradiation even without conventionally conjugated structures. Such unconventional luminescence is attributed to the clusteroluminogens formed by through-space electronic interactions of heteroatoms and phenyl rings. All the obtained polymers show excellent optical transparency, high and tunable refractive indices, low optical dispersions and good photopatternability, which make them promising materials in various advanced electronic and optoelectronic devices. The ring-opened polymers can also function as a lysosome-specific fluorescent probe in biological imaging.
\end{abstract}

\section{INTRODUCTION}

The construction of polymeric materials with novel structures, attractive properties and advanced applications is of great academic and industrial significance. Heterocyclic polymers are an important group of advanced functional materials and have gained enormous attention for decades owing to their unique mechanical, electrical and photophysical properties and high-tech applications in aerospace, manufacturing, chemical, electronic, and electrooptical industries. ${ }^{1-4}$ Among them, polymers with smallring heterocycles have recently received particular interest of polymer and materials scientists and have become valuable targets of synthesis. ${ }^{5-7}$ The unique strained rings in the polymer backbone can serve as mechanophores for the study of polymer mechanochemistry and allow the polymers to be good mechanoresponsive materials by undergoing predictable chemical transformations. ${ }^{8-10}$ However, such kind of polymers is normally prepared by attaching polymer chains to the modified small heterocycles, which generally requires tedious synthetic procedures or harsh reaction conditions. The lack of expedient synthetic strategy greatly limits the scope of small-ring heterocyclic polymers and hinders the exploration of their multifaceted applications. So far, efficient synthesis and property investigation of polymers with small-ring heterocycles as the repeating units are still rarely reported.

The presence of large numbers of small-ring heterocycles in a polymer backbone is very likely to endow the corresponding polymeric material with a variety of new interesting properties and advanced functionalities.,11-13 For example, the ring strain of these small cyclic units in polymer chains may enable the polymer to be transformed into new forms or structures with distinctive properties and performance in response to external stimuli. ${ }^{14,15}$ On the other hand, the introduction of numerous heteroatoms could bring the resulting polymers with intriguing biological activities or photophysical properties and potential applications in biomedical science, advanced optics, smart sensing materials, etc. ${ }^{16-18}$ For instance, some nonconjugated but heteroatom-rich natural products like 
starch, cellulose, protein, etc., ${ }^{19}$ and synthetic polymers including poly(amidoamine)s, ${ }^{20}$ polysiloxanes ${ }^{21}$, poly(maleic anhydride), ${ }^{22}$ etc., ${ }^{23,24}$ have been reported to show clusteroluminescence. They can emit visible light upon UV excitation in the condensed state even without any classic conjugated structures. These non-conjugated luminescent polymers further expand the scope of organic solid emitters and are well suited for biomedical applications due to their excellent biocompatibility and environmentally friendly nature. ${ }^{25,26}$ Although this unconventional luminescent phenomenon has aroused wide interest, the underlying emission mechanism is still under debate and needs to be more strongly supported by experimental evidence. ${ }^{27}$ The mechanistic understanding of such unconventional luminescence will provide useful information for the design of novel luminescent materials and help explain the autofluorescence of biomolecules. Therefore, it is highly desirable and well worth taking the challenge to prepare functional polymers that are composed of heteroatom-rich non-conjugated strained rings and investigate their photophysical properties and applications. It will be even more beneficial if such small-ring heterocyclic polymers could be accessed by simple synthetic routes.

Multicomponent polymerizations (MCPs), which are derived from the fascinating multicomponent reactions (MCRs), ${ }^{28-31}$ have drawn increasing attention and become a new research frontier in polymer chemistry in the past decade. ${ }^{32-38}$ The simultaneous incorporation of three or more monomers with different functional moieties in a one-pot MCP not only has the merits of simple synthetic and isolation procedures, high atom economy, good functional-group tolerance and high efficiency, but also greatly enriches the product structural diversity and endows the resulting polymers with tunable and multiple functionalities. ${ }^{39-41}$ A variety of multifunctional polymers with welldefined and complicated frameworks that are hard to be accessed by other conventional methods have been well constructed from facile MCPs. ${ }^{42,43}$ For example, Chang et al. have reported a series of facile and efficient $\mathrm{Cu}$-catalyzed multicomponent couplings of sulfonyl azides, alkynes and nucleophiles. ${ }^{44-47}$ Attracted by their unique advantages, some of them have been developed into efficient polymerization tools to synthesize high-molecular-weight functional polymers, such as poly( $N$-sulfonylamidine $) \mathrm{s},{ }^{40,48,49}$ poly( $N$-sulfonylimidate)s, ${ }^{48,50}$ and poly(phosphorus amidine)s. ${ }^{51}$ Recently, a copper-catalyzed three-component reaction of terminal alkynes, sulfonyl azides and carbodiimides (Scheme 1A) have caught our attention. ${ }^{52}$ This MCR can generate 2,4-diiminoazetidine derivatives, a multisubstituted nitrogen-bearing four-membered heterocyclic system, under mild conditions in excellent yields from readily available substrates. Different from most MCRsm involving terminal alkynes and sulfonyl azides, ${ }^{44,53-56}$ this reaction does not require an additional base as promoter possibly due to the inherent weak basicity of carbodiimdes. Therefore, the derived MCP is envisioned to be a powerful tool to generate functional polymers with small-ring heterocycles as building blocks.

In this work, we have successfully designed and developed a facile and efficient three-component polymerization route of terminal diynes, disulfonyl azides and car- bodiimides to produce functional polymers bearing heteroatom-rich multisubstituted azetidine rings (Scheme 1B). Four-membered heterocycles in the polymer backbone were generated in situ during the polymerization at room temperature and numerous heteroatoms were facilely incorporated into the polymer framework in one pot. The obtained azetidine-containing polymers easily undergo ring-opening post-modification in acidic condition to form another brand-new heteroatom-rich polymer structures in a fast and highly efficient manner. Interestingly, intrinsic visible emission was observed from the as-prepared polymer powders under UV or visible light irradiation, even though some of them lack conventional $\pi$-conjugation. The latent mechanism of such unconventional luminescence was carefully studied by experimental and theoretical analyses. The bioimaging applications, light refraction and photopatterning of these polymeric materials were also investigated in this work and the obtained results showed that they are good candidates as fluorescent agents for lysosome labeling and as coating materials in advanced electronic and photonic devices.

Scheme 1. (A) CuI-Catalyzed MCR toward 2,4Diiminoazetidine Derivatives. (B) Syntheses of Polymers with Small Heterocycles by One-Pot MCP.

(A)

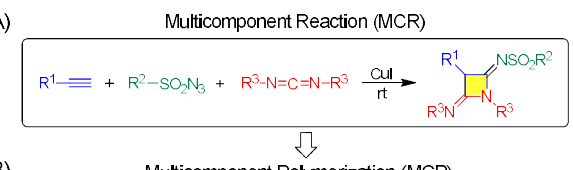

(B)

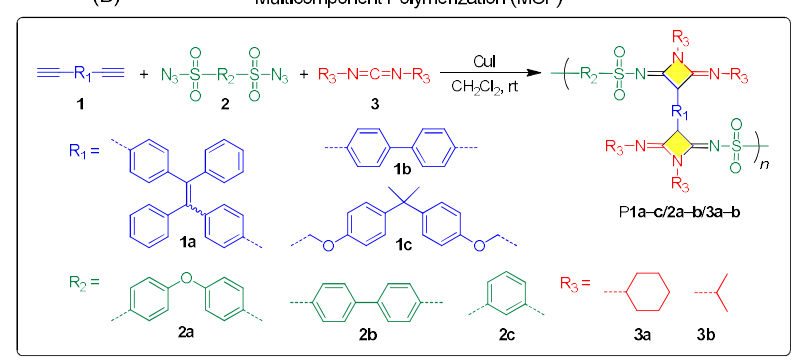

\section{RESULTS AND DISCUSSION}

\section{Polymerization}

The terminal diynes $\mathbf{1 b}-\mathbf{c}$ and disulfonyl azide $\mathbf{2 a}-\mathbf{c}$ used in this work were readily synthesized according to the literature methods. ${ }^{57,58}$ Diyne 1a, $N, N^{\prime}-$ dicyclohexylcarbodiimide (DCC) and $N, N^{\prime}$ diisopropylcarbodiimide (DIC) were commercially available and used without further purification. All the polymerizations were catalyzed by $\mathrm{CuI}$ and conducted under nitrogen at room temperature in a one-pot manner. To obtain soluble polymers with high molecular weights in high yields, we systematically optimized different reaction parameters using $\mathbf{1 a}, \mathbf{2 a}$ and $\mathbf{3 a}$ as the model monomers. The effect of monomer concentration on the polymerization was first investigated (Table S1). When the monomer concentration of $1 \mathrm{a}$ was $0.40 \mathrm{M}$, a polymer with a high molecular weight (24500) was obtained in a good yield (80.9\%). At this monomer concentration, we then examined solvent effect and found that $\mathrm{CH}_{2} \mathrm{Cl}_{2}$ was the best one among the tested solvents for this polymerization (Table 1, entries 1-3 and Table S2). The polymerizations also proceeded 
smoothly in tetrahydrofuran (THF) and chloroform $\left(\mathrm{CHCl}_{3}\right)$ to generate polymers with reasonable $M_{\mathrm{w}}$ and yield, whereas partial gelation occurred in dimethylacetamide possibly due to the formation of polymeric products with high molecular weight and poor solubility. The time course of the polymerization was then studied in $\mathrm{CH}_{2} \mathrm{Cl}_{2}$. Taking the $M_{\mathrm{w}}$ and $\oslash$ of the resulting polymer and the isolation yield into consideration, $24 \mathrm{~h}$ was adopted as the optimal reaction time (Table S3). Regarding the catalyst loading, the results in entries 3-6 of Table 1 showed that decreasing the amount of $\mathrm{CuI}$ from $20 \%$ equivalent to $10 \%$ equivalent exerted little influence on the polymerization results, affording a polymer with $M_{\mathrm{w}}$ of 21600 in $81.3 \%$ yield. Further reducing the catalyst loading to $5 \%$ equivalent, however, led to a decrease in both the $M_{\mathrm{w}}$ and yield. Although the addition of $30 \%$ equivalent of CuI gave a polymer with a higher $M_{\mathrm{w}}$ of 47400 , the $M_{\mathrm{n}}$ value remained almost unchanged. To make the polymerization more economic without deteriorating the polymerization efficiency, we thus preferred to use $10 \%$ equivalent as the catalyst dosage. The effect of temperature on the polymerization was also investigated. The results in Table S4 suggested that the polymerization efficiency can be improved by increasing the reaction temperature. The polymerization conducted at $40{ }^{\circ} \mathrm{C}$ produced P1a/2a/3a with a $M_{\mathrm{w}}$ of 23500 in $84.6 \%$ yield after reaction for merely $5 \mathrm{~h}$. On the other hand, almost no reaction occurred when the temperature was lowered to $0{ }^{\circ} \mathrm{C}$. Considering energy conservation and easy operation, we chose room temperature as the preferred reaction temperature.

Based on the optimized polymerization conditions, different monomer combinations were applied to test the robustness of this polymerization route and meanwhile enrich the polymer structures. As summarized in entries 7-11 of Table 1, in addition to DCC (3a), the present method was also applicable to DIC (3b) to generate P1a/2a/3b with a high $M_{\mathrm{w}}$ of 74500 in a good yield of $83.5 \%$. An insoluble gel was obtained when $N$-(3-dimethylaminopropyl)$N$-ethylcarbodiimide hydrochloride was employed to react with monomer $\mathbf{1 a}$ and $\mathbf{2 a}$. When less conjugated 4,4'diethynyl-1,1'-biphenyl (1b) was used to replace the tetraphenylethene (TPE)-containing diyne (1a), the polymerization still proceeded smoothly to yield P1b/2a/3a with the desired structure and a $M_{\mathrm{w}}$ of 10200 . Aliphatic diyne (1c) was also effective for this polymerization, giving a polymer with a high $M_{\mathrm{w}}(29200)$ in a reasonable yield $(78.9 \%)$. Regarding the monomer scope of disulfonyl azide, the polymerizations of $\mathbf{2 b}$ and $\mathbf{2 c}$ can also produce azetidine-containing polymeric products with moderate to good $M_{\mathrm{w}}$. These results indicated that we successfully developed a facile and powerful MCP tool for the construction of polymers consisting of heteroatom-rich azetidine rings from handy monomers. No byproduct was produced from this MCP except nitrogen gas, indicating its high atom economy and environmental friendliness.

Table 1. Multicomponent Polymerizations of Diynes 1, Disulfonyl Azide 2 and Carbodiimides $3^{a}$

\begin{tabular}{cccccccc}
\hline entry & monomers & solvent & Cul loading (\%) & yield (\%) & $M_{\mathrm{n}}{ }^{\mathrm{b}}$ & $M_{\mathrm{w}}{ }^{\mathrm{b}}$ & $\oplus^{\mathrm{b}}$ \\
\hline 1 & $\mathbf{1 a}+\mathbf{2 a}+\mathbf{3 a}$ & $\mathrm{THF}$ & 20 & 80.0 & 5800 & 12900 & 2.2 \\
2 & $\mathbf{1 a}+\mathbf{2 a}+\mathbf{3 a}$ & $\mathrm{CHCl}_{3}$ & 20 & 84.6 & 6400 & 16400 & 2.6 \\
$3^{c}$ & $\mathbf{1 a}+\mathbf{2 a}+\mathbf{3 a}$ & $\mathrm{CH}_{2} \mathrm{Cl}_{2}$ & 20 & 80.9 & 9000 & 24500 & 2.7 \\
4 & $\mathbf{1 a}+\mathbf{2 a}+\mathbf{3 a}$ & $\mathrm{CH}_{2} \mathrm{Cl}_{2}$ & 10 & 81.3 & 8100 & 21600 & 2.7 \\
5 & $\mathbf{1 a}+\mathbf{2 a}+\mathbf{3 a}$ & $\mathrm{CH}_{2} \mathrm{Cl}_{2}$ & 5 & 75.7 & 7000 & 16700 & 2.4 \\
6 & $\mathbf{1 a}+\mathbf{2 a}+\mathbf{3 a}$ & $\mathrm{CH}_{2} \mathrm{Cl}_{2}$ & 30 & 88.5 & 9300 & 47400 & 5.1 \\
7 & $\mathbf{1 a}+\mathbf{2 a}+\mathbf{3 b}$ & $\mathrm{CH}_{2} \mathrm{Cl}_{2}$ & 10 & 83.5 & 11000 & 74500 & 6.8 \\
8 & $\mathbf{1 b}+\mathbf{2 a}+\mathbf{3 a}$ & $\mathrm{CH}_{2} \mathrm{Cl}_{2}$ & 10 & 76.4 & 5000 & 10200 & 2.0 \\
9 & $\mathbf{1 c}+\mathbf{2 a}+\mathbf{3 a}$ & $\mathrm{CH}_{2} \mathrm{Cl}_{2}$ & 10 & 78.9 & 9400 & 29200 & 3.1 \\
10 & $\mathbf{1 a}+\mathbf{2 b}+\mathbf{3 a}$ & $\mathrm{CH}_{2} \mathrm{Cl}_{2}$ & 10 & 47.9 & 6100 & 9000 & 1.5 \\
11 & $\mathbf{1 a}+\mathbf{2 c}+\mathbf{3 a}$ & $\mathrm{CH}_{2} \mathrm{Cl}_{2}$ & 10 & 72.4 & 7900 & 13800 & 1.7 \\
\hline
\end{tabular}

${ }^{a}$ Carried out at room temperature under nitrogen for $24 \mathrm{~h},[\mathbf{1}]=[2]=0.40 \mathrm{M},[3]=0.96 \mathrm{M} .{ }^{b}$ Estimated by GPC in THF on the basis of a linear polystyrene calibration. $\oslash=$ polydispersity $=M_{\mathrm{w}} / M_{\mathrm{n}} .{ }^{c}$ Data taken from Table S1, entry 4.

\section{Structural Characterization}

To gain insight into the structures of the obtained polymers, model compound $\mathbf{4}$ was prepared by the one-pot three-component reaction of phenylacetylene, $p$ toluenesulfonyl azide and DCC (Figure 1A). Its structure was confirmed by HRMS (Figure S1), IR and NMR analysis. All the polymer structures were fully characterized and verified by standard spectroscopic techniques.

The characterization results of 4 and $\mathrm{P} \mathbf{1 a} / \mathbf{2 a} / \mathbf{3 a}$ together with the corresponding monomers $\mathbf{1 a}, \mathbf{2 a}$, and $\mathbf{3 a}$ are discussed here as examples. The IR spectrum of P1a/2a/3a shown in Figure S2 exhibited no characteristic absorption peaks of $\equiv \mathrm{C}-\mathrm{H}$ and $\mathrm{C} \equiv \mathrm{C}$ groups at 3275 and $2106 \mathrm{~cm}^{-1}$ in monomer $1 \mathrm{a}$ and the $\mathrm{N}_{3}$ stretching vibration band at 2158 and $2127 \mathrm{~cm}^{-1}$ in monomer $\mathbf{2 a}$. On the other hand, two new absorption bands at around 1760 and 1610 $\mathrm{cm}^{-1}$ emerged after the polymerization. The simulated IR spectrum of 4 calculated by B3LYP/6-31+G** (Figure S3) revealed that these two new bands resulted from the stretching vibrations of $\mathrm{C}=\mathrm{N}$ groups in the newly formed 2,4-diiminoazetidine frameworks.

${ }^{1} \mathrm{H}$ NMR analysis provided more detailed information on the polymer structure. As depicted in Figure $1 \mathrm{~B}-\mathrm{F}$, the spectrum of $\mathrm{P} 1 \mathrm{a} / \mathbf{2 a} / \mathbf{3 a}$ showed no peak associated with the resonances of the acetylene proton of $1 \mathbf{a}$ at $\delta 3.03$. The 
signals related to the aromatic protons in "b" positions of monomer $2 \mathrm{a}$ at $\delta 8.03$ shifted to the high field after the polymerization. The peak at $\delta 3.18$ arisen from the resonance of the protons in " $c$ " positions of DCC changed to two different peaks at $\delta 3.75$ and 2.96. Compared with the spectrum of model compound 4 , these two peaks can be readily assigned as the resonance signal of the cyclohexane proton in " $\mathrm{e}$ " and " $\mathrm{f}$ " position, respectively. Meanwhile, a new peak at $\delta 5.15$ was observed in the polymer spectrum, which was associated with the resonance of the " $\mathrm{d}$ " proton in the newly generated four-membered heterocycle. The ${ }^{13} \mathrm{C}$ NMR results in Figure $1 \mathrm{G}-\mathrm{K}$ further verified the polymer structure. No resonance peaks of the acetylene carbon atoms of 1a was observed in the polymer spectrum. Instead, the original acetylene carbons were transformed to the carbon atoms in " $\mathrm{h}$ " and " $\mathrm{j}$ " positions of the azetidine structure, which absorbed at $\delta 166.94$ and 60.75 , respectively. In addition, the " $\mathrm{e}$ " carbon of DCC was converted to the "i" carbon atom in the polymer structure and the corresponding resonance peak shifted from $\delta 140.0$ to $\delta 151.0$ after the polymerization. The resonance of the " $\mathrm{f}$ " carbon atoms of DCC at $\delta 55.9$ was split to two different peaks ("k" and "l") due to the formation of four-membered azaheterocycle. The peak assignments were further confirmed by the DEPT-135 and 2D NMR spectra of model compound 4 (Figure S4-6). Similar features were also observed in the characterization results of the other polymers (Figure S7-17). These results revealed that we indeed obtained the precise targeted polymer structures as shown in Scheme 1B.

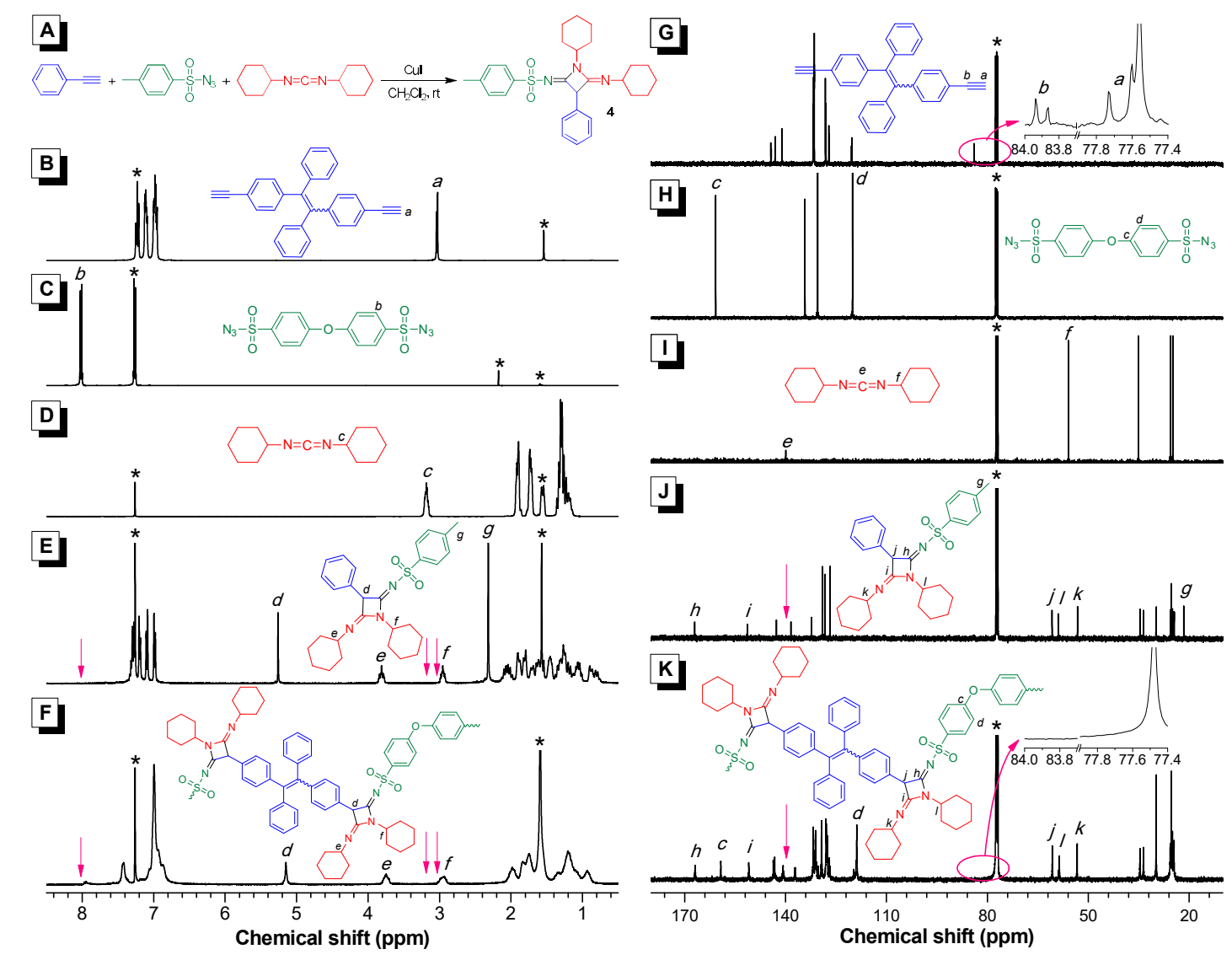

Figure 1. (A) Synthetic route to model compound 4. ${ }^{1} \mathrm{H}$ NMR spectra of (B) 1a, (C) 2a, (D) 3a, (E) 4 and (F) P1a/2a/3a in chloroform- $d .{ }^{13} \mathrm{C}$ NMR spectra of (G) 1a, (H) 2a, (I) 3a, (J) 4 and (K) P1a/2a/3a in chloroform- $d$. The solvent peaks are marked with asterisks.

\section{Acid-Mediated Ring-Opening Reaction}

Ring-opening reaction of small aza-heterocycles is a simple and efficient way for the generation of new nitrogen-rich structures. $^{59,60}$ To test the ring-opening possibility of the obtained polymers, an excess amount of aqueous $\mathrm{HCl}$ solution was added into the THF solution of P1a/2a/3a under stirring. After reaction for $30 \mathrm{~min}$, we characterized the polymer again and found that its structure obviously changed under acidic conditions. To reveal the postmodified polymer structure, a model reaction of $\mathbf{4}$ was carried out. Analysis by thin layer chromatography and ${ }^{1} \mathrm{H}$
NMR spectroscopy (Figure S18) indicated that the acidmediated reaction of $\mathbf{4}$ was very efficient and can nearly go to completion within $40 \mathrm{~min}$ at room temperature. The pure product $\mathbf{5}$ was collected as a white solid in a yield of $90.6 \%$ (Scheme 2A). Single crystals of $\mathbf{5}$ were successfully obtained from its $\mathrm{CH}_{2} \mathrm{Cl}_{2} / n$-hexane mixture and analysis by $\mathrm{X}$-ray diffraction revealed the presence of strong intramolecular hydrogen bonding between the $\mathrm{C}=\mathrm{O}$ and $\mathrm{N}-\mathrm{H}$ groups. The results from HRMS (Figure S19), IR, ${ }^{1} \mathrm{H}$ NMR and ${ }^{13} \mathrm{C}$ NMR spectroscopics, elemental analysis, and single crystal X-ray diffraction (Table S5) solidly demonstrated 
the generation of amide and amidine structures through the acid-mediated ring-opening reaction. DEPT-135 NMR, ${ }^{1} \mathrm{H}-{ }^{-1} \mathrm{H}$ COSY and HSQC spectra of model compound 5 were measured to assist the peak assignments (Figure S20-22).

Scheme 2. Ring-Opening Reaction of (A) 4 and (B) P1a-c/2a/3a. Inset: Single Crystal Structure of 5.

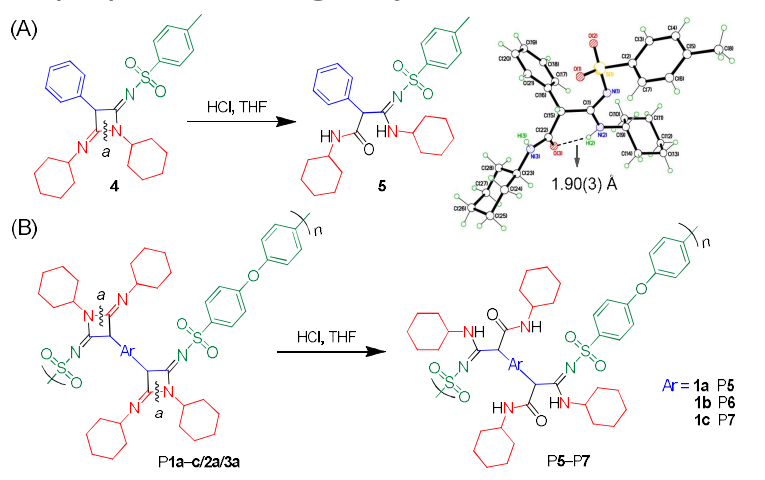

The ${ }^{1} \mathrm{H}$ NMR spectra of of $\mathrm{P} \mathbf{1 a} / \mathbf{2 a} / \mathbf{3 a}, \mathbf{5}$ and P5 are compared in Figure $2 \mathrm{~A}-\mathrm{C}$. It is very clear that the characteristic peaks at "d", "e" and "f" protons of P1a/2a/3a all shifted to new locations in the spectra of $\mathbf{5}$ and P5 due to the change in the local electron environment after the ring-opening process. Besides, new peaks ("i" and "j") associated with the resonance of $\mathrm{NH}$ protons were observed in the spectrum of $\mathbf{5}$. The spectrum of P5 largely resembled that of $\mathbf{5}$ in profile, although the resonance signal of the " $j$ " proton was difficult to be detected in the polymer spectrum. The weak "j" proton signal may be caused by the rigid polymer chain which slows down its relaxation. The presence of multiple hydrogen bonds in the polymer structure further causes it to shift downfield to overlap with the broad absorption of the aromatic protons. Together with the IR (Figure S23) and ${ }^{13} \mathrm{C}$ NMR (Figure S24) results, it is confirmed that the 2,4-diiminoazetidine units in the polymer backbone can smoothly undergo ring-opening reaction via cleavage of the $\mathrm{C}-\mathrm{N}$ bond at position "a" under acidic conditions (Scheme 2B) to produce a brand-new polymer skeleton with amide and amidine units. Other azetidinecontaining polymers obtained herein were also capable of undergoing such ring-opening reactions. The corresponding characterization data and spectra are provided in the Supporting Information (Figure S25-27). The GPC results (Figure S28 and characterization data of P5-7 in the supporting information) showed that the molecular weights and the shape of the GPC curves of the ring-opened polymers were generally similar to those of the corresponding azetidine-containing polymers, which implied that these ring-opening reactions involved little side reactions.

To investigate the efficiency of this ring-opening reaction, ${ }^{1} \mathrm{H}$ NMR spectroscopy was employed to monitor the structural change of $\mathrm{P} \mathbf{1 a} / \mathbf{2 a} / \mathbf{3 a}$ with time. As depicted in Figure 2D, the characteristic resonance peak at $\delta 5.16$ (d) significantly decreased and a new peak at $\delta 5.69$ (d') obviously appeared within $5 \mathrm{~min}$. The conversion efficiency from P1a/2a/3a to P5 can be estimated by calculating the integration of the peak at $\delta 5.16$ and 5.69 , which was determined to be $83 \%, 95 \%$ and $\sim 100 \%$ at a reaction time of 5, 15 and $30 \mathrm{~min}$, respectively. These results suggested that unlike most reported polymer reactions, ${ }^{61-63}$ this ringopening post-modification process was very fast and highly efficient.
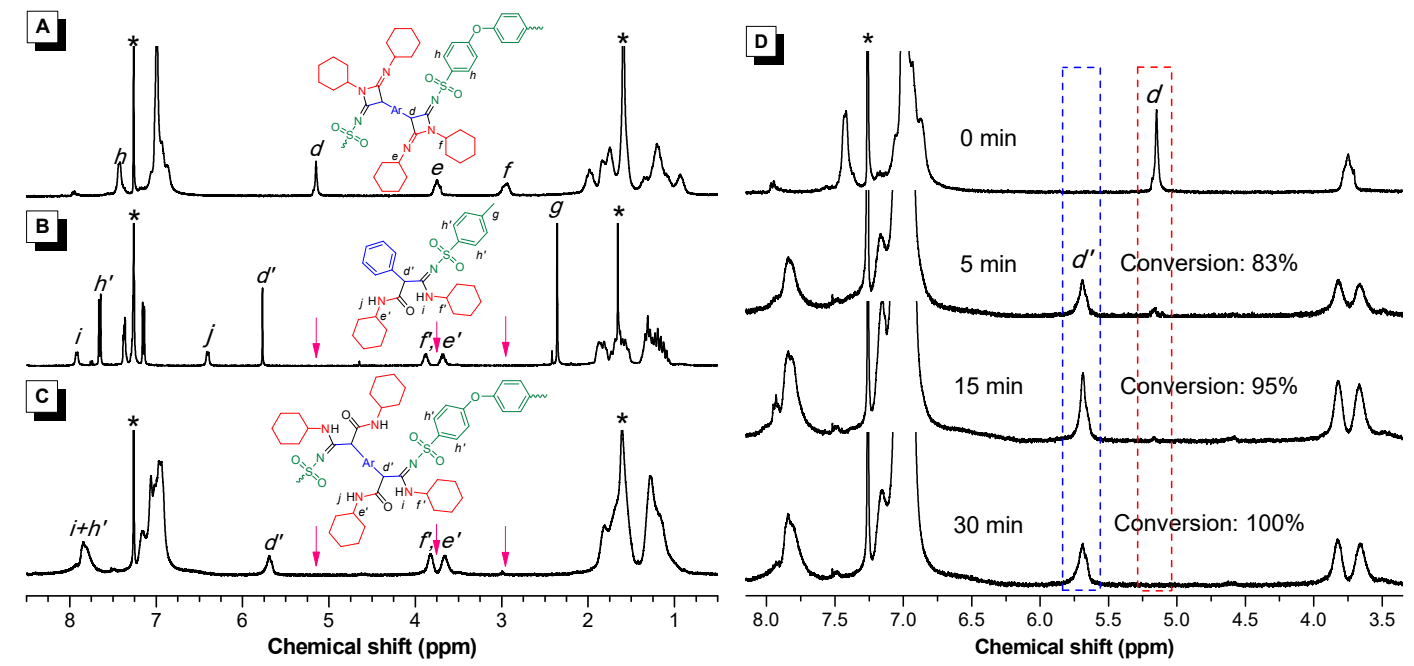

Figure 2. ${ }^{1} \mathrm{H}$ NMR spectra of (A) P1a/2a/3a, (B) 5 and (C) P5 (sample obtained from the ring-opening reaction for $30 \mathrm{~min}$ ) in chloroform- $d$. (D) ${ }^{1} \mathrm{H}$ NMR spectra of the polymer sample in chloroform- $d$ before and after ring-opening reaction for different time. The solvent peaks are marked with asterisks. "Ar" in the inset polymer structure represents $\mathrm{Ph}_{2} \mathrm{C}=\mathrm{CPh}$.

The thermal properties of all the obtained polymers were characterized by thermogravimetric analysis (TGA) and differential scanning calorimetry (DSC) measurements. The results in Figure S29 indicated that these polymers possessed good thermal and morphological stabilities. The decomposition temperature $\left(T_{\mathrm{d}}\right)$ of $\mathbf{P} \mathbf{1} \mathbf{a}-\mathbf{c} / \mathbf{2} \mathbf{a}-\mathbf{c} / \mathbf{3} \mathbf{a}-\mathbf{b}$ and
P5-7 at 5\% weight loss under nitrogen was in the range of 254-280 ${ }^{\circ} \mathrm{C}$ and $199-272{ }^{\circ} \mathrm{C}$, respectively. The thermal stablity of model compounds $\mathbf{4}$ and $\mathbf{5}$ was also measured to help investigate the influence of structural change caused by the ring-opening reaction on $T_{\mathrm{d}}$ (Figure S30). The results showed that the $T_{\mathrm{d}}$ of $\mathbf{4}$ and $\mathbf{5}$ was $185^{\circ} \mathrm{C}$ and $234^{\circ} \mathrm{C}$, 
respectively, which suggested that the ring-opening structure possessed a higher $T_{\mathrm{d}}$ than the corresponding azetidine-containing compound. DSC analysis shown in Figure S29B demonstrated that the glass transition temperature $\left(T_{\mathrm{g}}\right)$ of P1a/2c/3a, P1c/2a/3a, P5, and P7 was 182, 111, 192 , and $96^{\circ} \mathrm{C}$, respectively. The $T_{\mathrm{g}}$ of other polymers was not detected. The higher $T_{\mathrm{g}}$ of $\mathrm{P} \mathbf{1 a} / \mathbf{2 c} / \mathbf{3 a}$ and $\mathrm{P} \mathbf{5}$ could be ascribed to their higher conjugation and rigidity to restrict the segmental movement. The $T_{\mathrm{g}}$ values of the polymers before and after ring-opening were similar, which implied that the ring-opening reaction had little influence on $T_{\mathrm{g}}$. In addition, all the polymers possessed good solubility. They can be well dissolved in common organic solvents, such as toluene, DCM, $\mathrm{CHCl}_{3}, 1,2$-dichloroethane, and THF.

\section{Optical Transparency and Aggregation-Induced Emis- sion}

The absorption and transmission spectra in Figure S31 suggested that all the synthesized polymers possessed good optical transparency. They allowed almost all wavelengths of light in the visible spectral region to be transmitted through. The corresponding polymers before and after ring-opening reaction showed similar absorption spectra. Among them, P1a/2a-c/3a-b and P5 absorbed at the longest wavelength $(\sim 320 \mathrm{~nm})$ due to the presence of TPE units. The good optical transparency implied that the polymers were weakly conjugated. Such high optical clarity enables them to serve as candidate materials for photonic applications. ${ }^{64}$

TPE is an archetypical aggregation-induced emission (AIE) luminogen, which is virtually non-emissive in dilute solution but becomes highly fluorescent in the aggregated or solid state. ${ }^{65}$ Due to the presence of TPE moiety in the polymer skeletons, P1a/2a-c/3a-b and P5 all showed typical AIE features (Figure $3 \mathrm{~A}-\mathrm{B}$ and Figure S32-33). Taking P1a/2a/3a as an example, its THF solution emitted weakly at $489 \mathrm{~nm}$ with a fluorescent quantum yield $\left(\Phi_{\mathrm{F}}\right)$ of $1.4 \%$. With the gradual addition of water, a nonsolvent of the polymers, into their THF solutions, the photoluminescence (PL) intensity was steadily enhanced and finally reached the maximum at $90 \%$ water content. The PL intensity of $\mathbf{P} \mathbf{1 a} / \mathbf{2 a} / \mathbf{3 a}$ aggregates in THF/water mixture with $90 \%$ water fraction $\left(I_{90}\right)$ was 8 -fold higher than that in pure THF solution $\left(I_{0}\right)$. The AIE feature of P1a/2a/3a can be ascribed to the restriction of intramolecular motions in the aggregated state, which blocks the nonradiative decay pathway of the excited state to turn on the emission of the polymer.66,67 After ring-opening, the PL spectral shape and the wavelength of the emission maximum $\left(\lambda_{\mathrm{em}}\right)$ changed little but the AIE effect was obviously amplified. As summarized in Table S6, the $I_{90} / I_{0}$ value of P5 was determined to be 19 . The $\Phi_{\mathrm{F}}$ of its THF solutions was the same as that of P1a/2a/3a, whereas the $\Phi_{\mathrm{F}}$ of its solid powder $(27.1 \%)$ was much higher than that of P1a/2a/3a $(11.2 \%)$. These results indicated that a new polymeric material with brighter solid-state emission can be readily generated by the ring-opening post-modification of the azetidine-containing polymer. The single crystal analysis of 5 shown in Scheme 2A and Figure S34 suggested that there could exist many strong intra-and inter-chain hydrogen bonds in P5. These interactions will more efficiently restrict the intramolecular motions and rigidify the confor- mation of P5, thus leading to its stronger light emission in the solid state than that of $\mathrm{P} \mathbf{1 a} / \mathbf{2 a} / \mathbf{3 a}$.
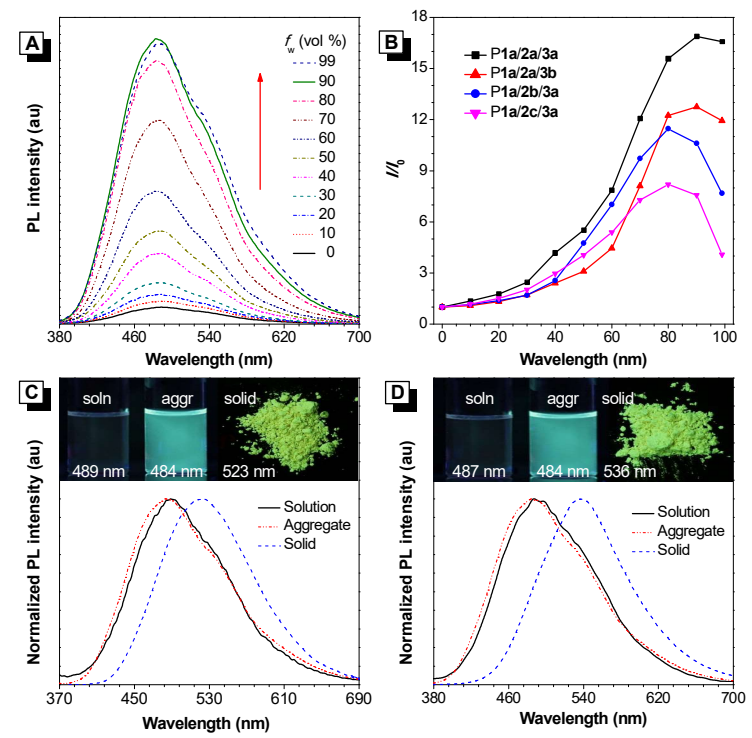

Figure 3. (A) PL spectra of P1a/2a/3a in THF and THF/water mixtures with different water fractions $\left(f_{\mathrm{w}}\right)$. (B) Plot of relative PL intensity $\left(I / I_{0}\right)$ versus the composition of the aqueous mixture of $\mathbf{P} \mathbf{1 a} / \mathbf{2 a}-\mathbf{c} / \mathbf{3 a}-\mathbf{b} . I_{0}=$ intensity at $f_{\mathrm{w}}=0 \%$. The normalized PL spectra of (C) P1a/2a/3a and (D) P1a/2a/3b. Inset: fluorescent photographs of (C) $\mathrm{P} 1 \mathbf{a} / \mathbf{2 a} / \mathbf{3 a}$ and (D) $\mathrm{P1a} / \mathbf{2 a} / \mathbf{3 b}$ in THF solution, THF/water mixture with $90 \%$ water fraction, and solid state taken under $365 \mathrm{~nm}$ UV irradiation. Solution concentration: $10 \mu \mathrm{M}$; excitation wavelength: $320 \mathrm{~nm}$.

\section{Unconventional Luminescence}

Intriguingly, the solid powders of $\mathrm{P} \mathbf{1 a} / \mathbf{2} \mathbf{a}-\mathbf{c} / \mathbf{3} \mathbf{a}-\mathbf{b}$ emitted an unusual yellow-green light with $\lambda_{\mathrm{em}}$ at $502-536 \mathrm{~nm}$ (Figure 3C-D and Figure S35). A significant red-shift in the $\lambda_{\text {em }}$ occurred from the solution or aggregates to the solid state. Such a yellow-green solid-state emission is much redder than that of the reported TPE-containing polymers with non-conjugated structures. ${ }^{40,68-70}$ This observation inspired us to further investigate the PL properties of the other two polymers without TPE fluorophores.

Conventional organic visible emitters are normally composed of large $\pi$-conjugated moieties. The emission of small $\pi$-systems typically falls in the UV spectral region because of the high energy associated with their electronic transitions. ${ }^{27,71}$ As the structures of P1b/2a/3a and $\mathrm{P} 1 \mathrm{c} / 2 \mathrm{a} / 3 \mathbf{3}$ show little through-bond conjugation (Scheme $1 \mathrm{~B})$, it is reasonable that their THF solutions merely emitted UV light (Figure 4). To our surprise, both of their solid powders exhibited obvious visible light emission with broad PL spectra under 365 nm UV irradiation. P1b/2a/3a powders emitted yellow-green light with $\lambda_{\mathrm{em}}$ at $521 \mathrm{~nm}$, while $\mathrm{P} 1 \mathrm{c} / \mathbf{2 a} / \mathbf{3 a}$ showed a blue solid-state emission at $465 \mathrm{~nm}$. The PL behaviors of their aggregates were also measured, which showed a minor peak in UV region and a dominant peak in the visible spectral range. The behaviors of the aggregates seemed like a transitional state between the solution and solid powders of the polymers. Similar phenomena were observed in model compound 4. The 
non-conjugated 4 surprisingly showed a deep-blue emission in the solid state while its dilute solution emitted no visible light at all.
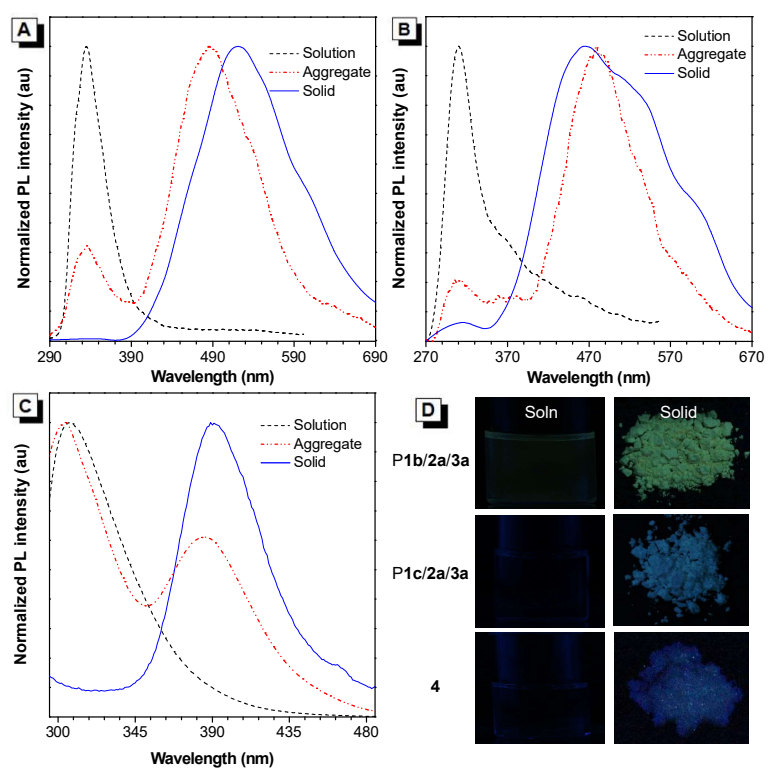

Figure 4. Normalized PL spectra of the THF solution, aggregates and solid powders of (A) P1b/2a/3a, (B) P1c/2a/3a and (C) model compound 4. (D) The associated fluorescent photos taken under $365 \mathrm{~nm}$ UV irradiation. The aggregates of P1b/2a/3a, P1c/2a/3a and 4 were obtained in THF/water mixture with water fraction of $80 \%$. Solution concentration: $10 \mu \mathrm{M}$; excitation wavelength: $260 \mathrm{~nm}$.

Moreover, a remarkable excitation-dependent emission characteristic, which is normally exhibited by carbonbased nanodots, ${ }^{72}$ was observed in all the obtained polymer powders. Taking P1a/2a/3a as an example, its emission peak gradually red-shifted from 518 to $592 \mathrm{~nm}$ when the excitation wavelength increased from 340 to $540 \mathrm{~nm}$ (Figure S36A and S37). The corresponding absorption and representative emission spectra of $\mathrm{P} \mathbf{1 a} / \mathbf{2 a} / \mathbf{3 a}$ are compared in Figure S36B. It is noteworthy that P1a/2a/3a absorbed almost no photons above $430 \mathrm{~nm}$ but it can be excited by light with much longer wavelengths. ${ }^{71}$ P1b/2a/3a and P1c/2a/3a showed similar behaviors (Figure S38-39). These results were indicative of the presence of different luminescent species in the solid state and each of them had its own excitation wavelength. ${ }^{73,74}$ The chromophores with longer-wavelength excitation and emission may derive from the varied clustered confor- mations generated through some inter- or intramolecular interactions in the polymer powders. ${ }^{75}$ Fluorescent images of the solid powders were taken under a fluorescent microscope with different band-pass excitation filters. As depicted in Figure S40, the fluorescence color of the polymers can be modulated from blue or green to yellow or orange and then even to red by simply changing the excitation wavelength. The red emission from these weakly or non-conjugated polymer structures suggested that the possible chromophores stemming from inter- or intramolecular interactions played a significant role in the polymer luminescence. These interesting discoveries promoted us to think deeply about what interactions exist and how they affect the PL behaviors of the polymers.

\section{What is the chromophore?}

Due to the complexity of polymer conformations, it is hard to get the aggregate structures and simulate the intra- or inter-chain interactions between the polymer chains. ${ }^{76}$ Hence, to answer the above question, we first carefully analyzed the crystal structure of model compound $\mathbf{4}$ to give some hints for the polymer behaviors. The results revealed that the two phenyl rings in $\mathbf{4}$ are stacked in a nearly face-to-face manner with a tilted angle of $14.21^{\circ}$ (Figure 5A and Figure S41). The shortest distance between the two stacked phenyl rings is $3.330 \AA$, indicating the existence of strong intramolecular through-space $\pi-\pi$ interaction. ${ }^{77}$ Additionally, the electron-rich oxygen and nitrogen atoms in $\mathbf{4}$ are arranged in close proximity and the distances between the adjacent heteroatoms range from 2.375 to $2.547 \AA$. This result suggests the presence of multiple through-space electronic interactions between the lone pairs. ${ }^{78,79}$ Furthermore, multiple intermolecular interactions such as $\mathrm{C}-\mathrm{H} \cdots \mathrm{O}\left(2.556-2.571 \AA\right.$, $\left.140.73-144.97^{\circ}\right)$ and $\mathrm{C}-\mathrm{H} \cdots \pi\left(3.661 \AA, 159.50^{\circ}\right)$ exist between the neighboring molecules (Figure S42). These synergetic intermolecular interactions rigidify the conformation of the molecules to facilitate and stabilize the formation of strong and extended through-space electronic conjugation in the solid state. ${ }^{27}$ The occurrence of intramolecular through-space conjugation in crystal of $\mathbf{4}$ was further verified by the density functional theory calculations using the B3LYP functional with the 6-31G(d) basis set (Figure 5B). Obvious transannular $\pi$-electron cloud overlapping between the two cofacial phenyl rings of $\mathbf{4}$ was observed in its LUMO+1 and LUMO+2 orbitals. Meanwhile the lone pairs of heteroatoms further favor the formation of a large $\pi$-conjugation as suggested by the HOMO and LUMO orbitals of 4 . 

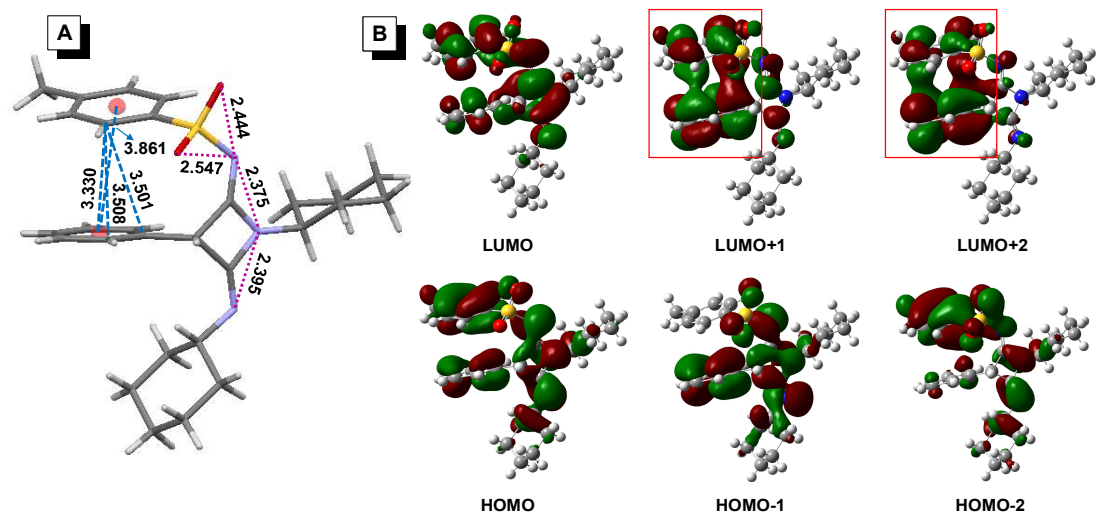

Figure 5. (A) Crystal structure of model compound 4 with indicated distances $(\AA ̊)$ between $\pi-\pi$ stacked aromatic rings and distances between atoms with lone pairs. (B) Molecular orbital amplitude plots of HOMO and LUMO of 4 in the ground state calculated by B3LYP/6-31G(d). The red rectangles indicate the through-space $\pi-\pi$ interaction.

Similar through-space conjugation is also likely to occur in polymer powders. As the presence of intra- or interchain interactions may influence the chemical binding states of the involved atomic electrons, we tried to use the $\mathrm{X}$-ray photoelectron spectroscopy (XPS) to investigate the interactions in polymer samples. By comparing the XPS results of $\mathbf{4}, \mathrm{P} \mathbf{1 a} / \mathbf{2 a} / \mathbf{3 a}$ and $\mathrm{P} \mathbf{1 b} / \mathbf{2 a} / \mathbf{3 a}$, we found that there is an obvious difference in the lineshapes of their high-resolution $\mathrm{N}$ 1s spectrum (Figure 6). The $\mathrm{N}$ 1s XPS signal of $\mathbf{4}$ can be deconvoluted into three peaks. The two main peaks at 400.6 and $399.0 \mathrm{eV}$ can be readily assigned to $\mathrm{N}=\mathrm{C}$ and $\mathrm{N}-\mathrm{C}$, respectively. The small peak at $399.9 \mathrm{eV}$ may result from the aforementioned intramolecular through-space interactions, which change the chemical environment of $\mathrm{N} 1 \mathrm{~s}$ with other atoms. By comparison, the new peak at about $399.8 \mathrm{eV}$ significantly amplifies while the ratio of $\mathrm{N}=\mathrm{C}$ peak decreases markedly in the $\mathrm{N} 1 \mathrm{~s}$ spectrum of the polymer samples. These experimental results indicate that there should exist more or stronger throughspace interactions in polymer powders which can occur both inside and between the polymer chains, such as the possible presence of $\mathrm{C}=\mathrm{N} \cdots \mathrm{N}$ or $\mathrm{C}=\mathrm{N} \cdots \pi$ interactions, etc.
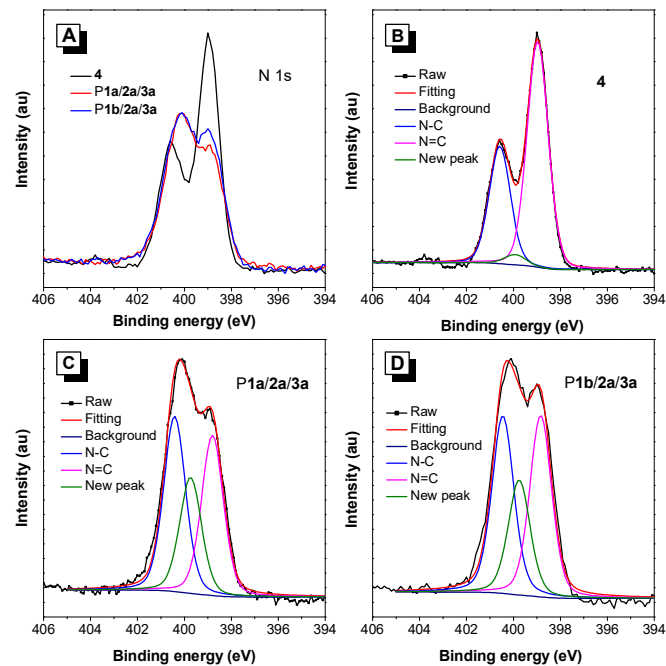

Figure 6. High-resolution XPS spectra of $N$ 1s of $\mathbf{4}, \mathrm{P} \mathbf{1 a} / \mathbf{2 a} / \mathbf{3 a}$ and $\mathrm{P} \mathbf{1 b} / \mathbf{2 a} / \mathbf{3 a}$.

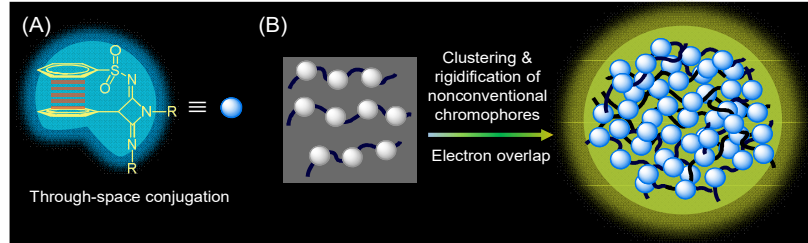

Figure 7. Schematic illustration of the unconventional luminescence of (A) model compound $\mathbf{4}$ and (B) polymers.

Based on these results, we propose that the presence of strong through-space $\pi-\pi$ interaction and multiple lonepair electronic interactions in the solid state collectively yields a through-space conjugated chromophore as illustrated in Figure 7A. In polymer powders, the chain entanglement and intra-/interchain interactions will facilitate the clustering and conformational rigidification of the nonconventional chromophores in the condensed polymer chains, which will further increase the chance for the lonepair electrons and $\pi$ electrons to approach each other and delocalize through heteroatom $\cdots \pi$ and $\pi-\pi$ interactions. Consequently, "clustered chromophores", namely clusteroluminogens, are formed and the through-space conjugation is amplified in polymers (Figure 7B). The extended electronic conjugation lowers the energy gap, thus explaining the remarkable red-shifted emission of $\mathrm{P} 1 \mathbf{a} / \mathbf{2 a}-\mathbf{c} / \mathbf{3 a}-\mathbf{b}$ powders and the abnormal visible solidstate fluorescence of the weakly conjugated $4, \mathrm{P} \mathbf{1 b} / \mathbf{2 a} / \mathbf{3 a}$ and $\mathbf{P} \mathbf{1 c} / \mathbf{2 a} / \mathbf{3 a}$. These through-space and rigidifying interactions, however, are impaired in the solution state due to the active intramolecular motions of the molecules, such as the free rotations of the phenyl rings and cyclohexyl rings and the strong vibration of the $\mathrm{O}=\mathrm{S}=0$ group. That is why no visible emission was observed in dilute solutions. The interesting excitation-dependent emission of the solid powders should be attributed to the heterogeneity of the clusteroluminogens. The intrinsic complexity and polydispersity of polymer give rise to various conformations and sizes of the clusters, thus leading to the presence of different luminescent species with different degrees of throughspace electronic conjugation. These unconventional through-space conjugated (macro)molecules not only fur- 
ther broaden the scope of organic fluorophores but also provide good models for the mechanistic understanding of clusteroluminescence.

\section{Cell Imaging}

The good solid-state luminescence of the obtained polymers encouraged us to explore their applications in cell imaging. The sizes and the morphologies of the nanoparticles (NPs) of P1a/2a/3a and P5 were characterized by dynamic light scattering (DLS) and SEM measurements. The results showed that spherical nanoparticles of P1a/2a/3a and P5 with effective diameters of $122 \mathrm{~nm}$ $(\mathrm{PDI}=0.044)$ and $112 \mathrm{~nm}(\mathrm{PDI}=0.145)$ were obtained, respectively (Figure S43). The cell staining capability of P1a/2a/3a and P5 NPs was first tested using a confocal laser scanning microscope. As depicted in Figure S44, remarkable blue fluorescence was observed in HeLa cells at an excitation wavelength of $405 \mathrm{~nm}$ after incubation with $120 \mu \mathrm{g} / \mathrm{mL}$ P5 NPs, whereas P1a/2a/3a NPs showed no obvious fluorescence signal. These results suggested that the ring-opening reaction can endow the resulting polymers with good cell staining ability. Closer inspection revealed that P5 NPs may specifically localize and stain the lysosomes in living HeLa cells. To prove it, a co-staining experiment with LysoTracker Red DND-99 (LTR), a commercial lysosome imaging agent, was carried out. The cell staining regions of P5 NPs and LTR overlapped with near perfection (Figure 8). The Pearson's correlation coefficient, a parameter commonly used to quantify the overlap extent, ${ }^{80}$ was calculated to be 0.96 . The good specificity of P5 NPs to lysosomes might be ascribed to their possible cellular uptake mechanism of the endocytosis pathway together with the weak alkaline of the polymer structure. ${ }^{81-85}$ The cytotoxicity of P5 NPs was evaluated by 3-(4,5-dimethyl-2thiazolyl)-2,5-diphenyltetrazolium bromide (MTT) cellviability assay. As shown in Figure S45, the cell viability remained almost $80 \%$ at a $\mathbf{P 5}$ concentration of up to 150 $\mu \mathrm{g} / \mathrm{mL}$, suggesting that P5 has low cytotoxicity to HeLa cells. Moreover, the fluorescence intensity of P5 NPs retained over $80 \%$ of its initial value after continuous irradiation with excitation at $405 \mathrm{~nm}$ ( $2 \%$ laser power) for $5 \mathrm{~min}$, indicative of its excellent photo-bleaching resistance (Figure S46). Therefore, the ring-opened polymer P5 is a good lysosome-specific fluorescent nanoprobe. In addition, the cell-imaging performance of the NPs of $\mathbf{4}$ and $\mathbf{5}$ was also conducted under the same conditions as those of the polymer NPs. The obtained results shown in Figure S47 and S48 suggested that polymer NPs showed obvious superiority than the small molecules in terms of size distribution, morphology, fluorescence brightness, etc.

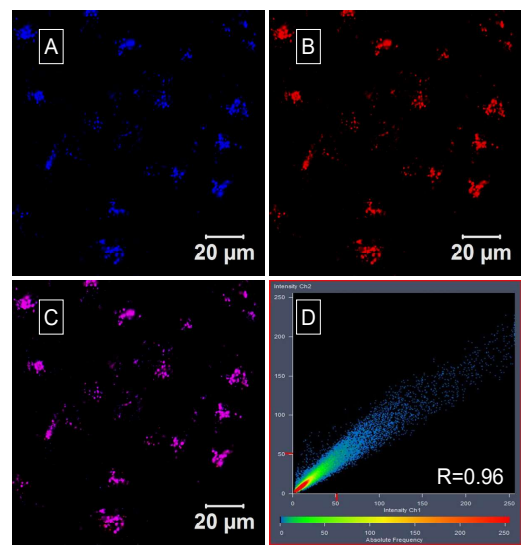

Figure 8. Confocal images of HeLa cells stained with (A) P5 $(120 \mu \mathrm{g} / \mathrm{mL}, 18 \mathrm{~h})$ and (B) LysoTracker Red (LTR, $50 \mathrm{nM}, 10$ min). (C) Merged image of panels A and B. (D) Scatter plot indicating an overlap coefficient between the imaging result of P5 and LTR (inset: calculated Pearson's correlation coefficient). Excitation wavelength: $405 \mathrm{~nm}$ (P5) and $543 \mathrm{~nm}$ (LTR); emission filter: 410-509 nm (P5) and 560-681 nm (LTR).

\section{Light Refraction and Photopatterning}

Heteroatoms are well-known contributors for the increase of refractive index $(n) .{ }^{86}$ Our designed heteroatom-rich polymers are thus expected to show high $n$ values. Thanks to their good solubility and film-forming ability, tough polymer thin films can be easily fabricated by spin-coating process. As summarized in Figure 9A and Table S7, the thin films of the azetidine-containing polymers (P1/2/3) indeed showed high $n$ values of 1.767-1.619 in the spectral region of $380-890 \mathrm{~nm}$. Their $n$ values at $632.8 \mathrm{~nm}\left(n_{632.8}\right)$ were in the range of 1.659-1.627, which are much higher than those of conventional optical plastics, such as poly(methyl methacrylate) ( $n=1.497-1.489)$ and polycarbonate $(n=1.593-1.576) .{ }^{87}$ On the other hand, all the ringopened polymers (P5-7) exhibited relatively lower $n$ values ranging from 1.710 to 1.600 with $n_{632.8}$ values of 1.635-1.606. These results suggested that the light refraction of the azetidine-containing polymers can be modulated not only by varying the monomer structure but also by ring-opening reaction. In addition to the high light refractivity, both $\mathrm{P} 1 / 2 / 3$ and $\mathrm{P5}-\mathbf{7}$ possessed very small optical aberrations. Their Abbé number $\left(\nu_{\mathrm{D}}\right)$ and chromatic dispersion $(D)$ values were calculated to be 47.155-18.243 and $0.055-0.021$, respectively. Detailed calculation methods are provided in Table S5. Moreover, these polymers were found to be photosensitive under the exposure of strong UV light. The refractive indices gradually decreased as the UV irradiation time went on (Figure S49 and Table S8). 


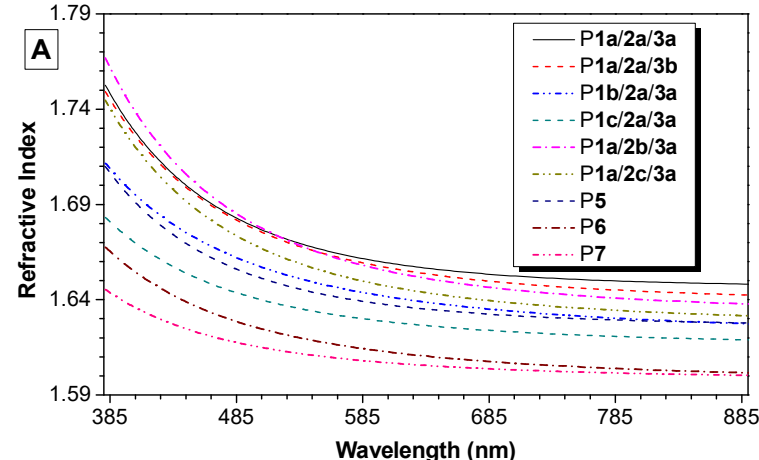

B

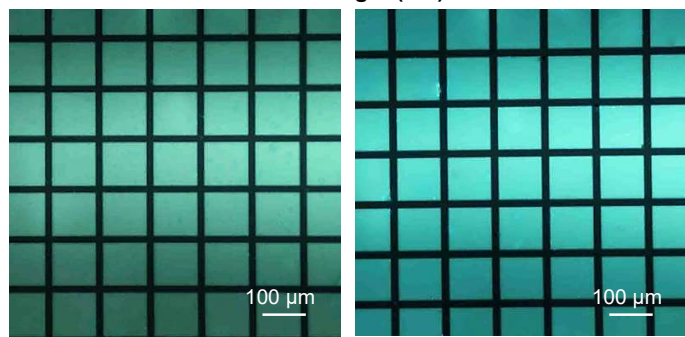

Figure 9. (A) Wavelength dependence of refractive indices of thin films of P1a-c/2a-c/3a-b and P5-P7. (B) Twodimensional fluorescent photopatterns of (B) P1a/2/3a and (C) P5 taken under 330-380 nm UV illumination.

Taking advantage of the good photosensitivity and efficient solid-state emission of the polymers, we successfully fabricated well-resolved two-dimensional fluorescent photopatterns by UV irradiation of the thin films of P1a/2a/3a and P5 on silicon wafers through a copper mask (Figure 9B). The emission of the exposed lines was quenched possibly due to the photo-oxidation process, ${ }^{88-90}$ whereas the unexposed squares remained brightly emissive. Clearly, the present polymers can be used as photoresist materials for the creation of fluorescent images. It is worth noting that the polymers are stable under the exposure of normal room light (see supporting information for details). Together with their good processability, excellent optical transparency, high and tunable refractive indices, and low chromatic dispersion, they are promising to serve as functional coating materials in various advanced electronic and photonic devices.

\section{CONCLUSIONS}

In summary, we have developed a facile one-pot multicomponent polymerization route to functional polymers with unique multisubstituted four-membered heterocyclic structures. This synthetic strategy enjoys the advantages of readily available monomers, simple operation, high efficiency, mild condition, environmental friendliness, and high atom economy. The strained rings in the polymer main chains enable them to efficiently undergo ringopening post-modification under simple acidic conditions to transform into new polymers with amide and amidine units. This feature not only enriches the polymer structures but also greatly tunes the polymer properties and broadens their application scopes. It is noteworthy that the obtained azetidine-containing polymers showed obvious solid-state luminescence despite of the absence of large $\pi$ - conjugated structures. Experimental results and theoretical analyses demonstrated that the clustering of heteroatoms and conformational rigidification-induced formation of efficient through-space conjugation played an important role in such unconventional luminescence phenomenon. XPS technique was innovatively employed to provide direct experimental evidence for the clusteroluminescence mechanism of polymers, which could be further extended for the mechanistic study of other unconventional luminescent systems. Compared with the parent polymers, the ring-opened polymer P5 exhibits brighter solid-state emission and better cytocompatibility, which can be utilized as a lysosome-specific fluorescent probe in biological imaging. Moreover, the obtained polymers all possess good filmforming ability, excellent optical transparency, high and tunable refractive indices, small optical aberrations, and good photopatternability. The facile synthetic strategy, systematic study of structure-property relationship and fascinating functionalities of the obtained polymers in this work will promote further research on the design, construction, modification, and functionalization of diverse polymers with small heterocycles.

\section{ASSOCIATED CONTENT}

\section{Supporting Information}

Details of the materials, methods, synthetic procedures, characterization data (HRMS, IR, NMR, TGA, DSC, etc.), and crystallographic data; effect of monomer concentration and time course on the polymerization; photophysical properties of the model compound and polymers; cell imaging and light refraction data. This material is available free of charge via the Internet at http://pubs.acs.org.

\section{AUTHOR INFORMATION}

\section{Corresponding Author}

*chjacky@ust.hk

*tangbenz@ust.hk

\section{Author Contributions}

${ }^{\#}$ T. Han and H. Deng contributed equally to this work.

\section{Notes}

The authors declare no competing financial interest.

\section{ACKNOWLEDGMENT}

We are grateful for financial support from the National Science Foundation of China (21788102, 21490570 and 21490574), the Research Grants Council of Hong Kong (16308116, 16305014 and 16303815), the Innovation and Technology Commission (ITC-CNERC14SC01) and the Science and Technology Plan of Shenzhen (JCYJ20160229205601482 and JCYJ20140425170011516).

\section{REFERENCES}

(1) Gunes, S.; Neugebauer, H.; Sariciftci, N. S. Chem. Rev. 2007, 107, 1324.

(2) Gribble, G. W.; Joule, J. A. Progress in Heterocyclic Chemistry; Elsevier: Oxford, 2016.

(3) Lu, L. Y.; Chen, W.; Xu, T.; Yu, L. P. Nat. Commun. 2015, 6, 7327.

(4) Yang, G. M.; Liu, L. B.; Yang, Q.; Lv, F. T.; Wang, S. Adv. Funct. Mater. 2012, 22, 736. 
(5) Rotstein, B. H.; Zaretsky, S.; Rai, V.; Yudin, A. K. Chem. Rev. 2014, 114, 8323

(6) Li, J.; Nagamani, C.; Moore, J. S. Acc. Chem. Res. 2015, 48, 2181.

(7) Caruso, M. M.; Davis, D. A.; Shen, Q.; Odom, S. A.; Sottos, N. R.; White, S. R.; Moore, J. S. Chem. Rev. 2009, 109, 5755.

(8) Chen, Y. L.; Spiering, A. J. H.; Karthikeyan, S.; Peters, G. W. M.; Meijer, E. W.; Sijbesma, R. P. Nature Chem. 2012, 4, 559.

(9) Akbulatov, S.; Tian, Y. C.; Boulatov, R. J. Am. Chem. Soc. 2012, 134,7620 .

(10) Lee, B.; Niu, Z. B.; Wang, J. P.; Slebodnick, C.; Craig, S. L. J. Am. Chem. Soc. 2015, 137, 10826.

(11) Hodgson, J. L.; Coote, M. L. Macromolecules 2005, 38, 8902.

(12) Banert, K.; Grimme, S.; Herges, R.; Hess, K.; Kohler, F.; Muck-Lichtenfeld, C.; Wurthwein, E. U. Chem. Eur. J. 2006, 12, 7467.

(13) Xu, H. D.; Zhou, H.; Pan, Y. P.; Ren, X. T.; Wu, H.; Han, M.; Han, R. Z.; Shen, M. H. Angew. Chem. Int. Ed. 2016, 55, 2540.

(14) Chen, Z. X.; Mercer, J. A. M.; Zhu, X. L.; Romaniuk, J. A. H.; Pfattner, R.; Cegelski, L.; Martinez, T. J.; Burns, N. Z.; Xia, Y. Science 2017, 357, 475 .

(15) Ramirez, A. L. B.; Kean, Z. S.; Orlicki, J. A.; Champhekar, M.; Elsakr, S. M.; Krause, W. E.; Craig, S. L. Nature Chem. 2013, 5, 757.

(16) Wang, Z. X.; Ding, S. N. Anal. Chem. 2014, 86, 7436.

(17) Griebel, J. J.; Namnabat, S.; Kim, E. T.; Himmelhuber, R.; Moronta, D. H.; Chung, W. J.; Simmonds, A. G.; Kim, K. J.; van der Laan, J.; Nguyen, N. A.; Dereniak, E. L.; Mackay, M. E.; Char, K.; Glass, R. S.; Norwood, R. A.; Pyun, J. Adv. Mater. 2014, 26, 3014.

(18) van Dijk, M.; Rijkers, D. T. S.; Liskamp, R. M. J.; van Nostrum, C. F.; Hennink, W. E. Bioconjugate Chem. 2009, 20, 2001.

(19) Gong, Y. Y.; Tan, Y. Q.; Mei, J.; Zhang, Y. R.; Yuan, W. Z.; Zhang, Y. M.; Sun, J. Z.; Tang, B. Z. Sci. China Chem. 2013, 56, 1178

(20) Wang, D. J.; Imae, T. J. Am. Chem. Soc. 2004, 126, 13204.

(21) Niu, S.; Yan, H. X.; Chen, Z. Y.; Li, S.; Xu, P. L.; Zhi, X. L. Polym. Chem. 2016, 7, 3747.

(22) Zhao, E.; Lam, J. W. Y.; Meng, L. M.; Hong, Y.; Deng, H. Q.; Bai, G. X.; Huang, X. H.; Hao, J. H.; Tang, B. Z. Macromolecules 2015, 48,64 .

(23) Zhou, Q.; Cao, B. Y.; Zhu, C. X.; Xu, S.; Gong, Y. Y.; Yuan, W. Z.; Zhang, Y. M. Small 2016, 12, 6586.

(24) Pucci, A.; Rausa, R.; Ciardelli, F. Macromol. Chem. Phys. 2008, 209, 900.

(25) Ye, R. Q.; Liu, Y. Y.; Zhang, H. K.; Su, H. F.; Zhang, Y. L.; Xu, L. G.; Hu, R. R.; Kwok, R. T. K.; Wong, K. S.; Lam, J. W. Y.; Goddard, W. A.; Tang, B. Z. Polym. Chem. 2017, 8, 1722.

(26) Zhang, X. H.; Shi, J.; Shen, G. Y.; Gou, F.; Cheng, J. H.; Zhou, X. G.; Xiang, H. F. Mater. Chem. Front. 2017, 1, 1041.

(27) Yuan, W. Z.; Zhang, Y. M. J. Polym. Sci., Part A: Polym. Chem. 2017, 55, 560 .

(28) Robotham, C. V.; Baker, C.; Cuevas, B.; Abboud, K.; Wright, D. L. Mol. Divers. 2003, 6, 237.

(29) Ochiai, B.; Ogihara, T.; Mashiko, M.; Endo, T. J. Am. Chem. Soc. 2009, 131, 1636.

(30) Espeel, P.; Goethals, F.; Du Prez, F. E. J. Am. Chem. Soc. 2011, 133, 1678 .

(31) Blasco, E.; Sims, M. B.; Goldmann, A. S.; Sumerlin, B. S.; Barner-Kowollik, C. Macromolecules 2017, 50, 5215.

(32) Kreye, 0.; Toth, T.; Meier, M. A. R. J. Am. Chem. Soc. 2011, 133, 1790.

(33) Liu, Y.; Qin, A. J.; Tang, B. Z. Prog. Polym. Sci. 2018, 78, 92.

(34) Sehlinger, A.; Dannecker, P. K.; Kreye, O.; Meier, M. A. R. Macromolecules 2014, 47, 2774

(35) Xue, H. D.; Zhao, Y.; Wu, H. B.; Wang, Z. L.; Yang, B.; Wei, Y.; Wang, Z. M.; Tao, L. J. Am. Chem. Soc. 2016, 138, 8690.

(36) Kakuchi, R. Angew. Chem. Int. Ed. 2014, 53, 46.

(37) Deng, X. X.; Du, F. S.; Li, Z. C. ACS Macro Lett. 2014, 3, 667

(38) Hu, R. R.; Li, W. Z.; Tang, B. Z. Macromol. Chem. Phys. 2016, $217,213$.
(39) Long, Z.; Mao, L. C.; Liu, M. Y.; Wan, Q.; Wan, Y. Q.; Zhang, X. Y.; Wei, Y. Polym. Chem. 2017, 8, 5644.

(40) Deng, H. Q.; Zhao, E. G.; Li, H. K.; Lam, J. W. Y.; Tang, B. Z. Macromolecules 2015, 48, 3180 .

(41) Kim, H.; Bang, K. T.; Choi, I.; Lee, J. K.; Choi, T. L. J. Am. Chem. Soc. 2016, 138, 8612.

(42) Leitch, D. C.; Kayser, L. V.; Han, Z. Y.; Siamaki, A. R.; Keyzer, E. N.; Gefen, A.; Arndtsen, B. A. Nat. Commun. 2015, 6, 7411.

(43) Wei, B.; Li, W. Z.; Zhao, Z. J.; Qin, A. J.; Hu, R. R.; Tang, B. Z. J. Am. Chem. Soc. 2017, 139, 5075.

(44) Bae, I.; Han, H.; Chang, S. J. Am. Chem. Soc. 2005, 127, 2038.

(45) Yoo, E. J.; Bae, I.; Cho, S. H.; Han, H.; Chang, S. Org. Lett. 2006, 8,1347 .

(46) Cho, S. H.; Yoo, E. J.; Bae, L.; Chang, S. J. Am. Chem. Soc. 2005, 127, 16046.

(47) Kim, S. H.; Park, S. H.; Choi, J. H.; Chang, S. Chem. Asian J. 2011, 6, 2618.

(48) Lee, I. H.; Kim, H.; Choi, T. L. J. Am. Chem. Soc. 2013, 135, 3760

(49) Zhang, Z.; You, Y. Z.; Wu, D. C.; Hong, C. Y. Macromolecules 2015, 48, 3414

(50) Kim, H.; Choi, T. L. Acs Macro Lett. 2014, 3, 791.

(51) Xu, L. G.; Hu, R. R.; Tang, B. Z. Macromolecules 2017, 50, 6043

(52) Xu, X. L.; Cheng, D. P.; Li, J. H.; Guo, H. Y.; Yan, J. Org. Lett. 2007, 9, 1585.

(53) Yoo, E. J.; Ahlquist, M.; Bae, I.; Sharpless, K. B.; Fokin, V. V.; Chang, S. J. Org. Chem. 2008, 73, 5520.

(54) Cui, S. L.; Lin, X. F.; Wang, Y. G. Org. Lett. 2006, 8, 4517.

(55) Namitharan, K.; Pitchumani, K. Org. Lett. 2011, 13, 5728.

(56) Zhou, W.; Zhang, M.; Li, H. H.; Chen, W. Z. Org. Lett. 2017, 19,10 .

(57) Wu, H. Q.; Li, H. K.; Kwok, R. T. K.; Zhao, E. G.; Sun, J. Z.; Qin, A. J.; Tang, B. Z.Sci. Rep. 2014, 4, 5107

(58) Katritzky, A. R.; Rogers, J. W.; Witek, R. M.; Vakulenko, A. V.; Mohapatra, P. P.; Steel, P. J.; Damavarapu, R. J. Energ. Mater. 2007, 25, 79.

(59) Wang, Y.; Chi, Y.; Zhang, W. X.; Xi, Z. F. J. Am. Chem. Soc. 2012, 134, 2926.

(60) Bo Wang, Reactivity of Four-Membered Aza-Heterocycles Based on Carbodiimide, Master Degree Thesis, Zhejiang University of Technology, 2013.

(61) Zhang, J.; Wang, W. J.; Liu, Y.; Sun, J. Z.; Qin, A. J.; Tang, B. Z. Macromolecules 2017, 50, 8554.

(62) Wang, W. J.; Shi, Y.; Wang, X.; Qin, A. J.; Sun, J. Z.; Tang, B. Z. Polym. Chem. 2017, 8, 2630.

(63) Wang, X.; Sun, J. Z.; Tang, B. Z. Prog. Polym. Sci., 2017, https://doi.org/10.1016/j.progpolymsci.2017.11.004.

(64) Yoon, J.; Mathers, R. T.; Coates, G. W.; Thomas, E. L. Macromolecules 2006, 39, 1913.

(65) Zhao, Z. J.; Lam, J. W. Y.; Tang, B. Z. J. Mater. Chem. 2012 $22,23726$.

(66) Mei, J.; Leung, N. L. C.; Kwok, R. T. K.; Lam, J. W. Y.; Tang, B. Z. Chem. Rev. 2015, 115, 11718.

(67) Wang, C.; Li, Z. Mater. Chem. Front., 2017, 1, 2174.

(68) Liu, Y. J.; Gao, M.; Lam, J. W. Y.; Hu, R. R.; Tang, B. Z. Macromolecules 2014, 47, 4908.

(69) Zhang, X. Y.; Zhang, X. Q.; Yang, B.; Liu, M. Y.; Liu, W. Y.; Chen, Y. W.; Wei, Y. Polym. Chem. 2013, 4, 4317.

(70) Wang, Z. K.; Chen, S. J.; Lam, J. W. Y.; Qin, W.; Kwok, R. T. K.; Xie, N.; Hu, Q. L.; Tang, B. Z. J. Am. Chem. Soc. 2013, 135, 8238.

(71) Hoffmann, R. Acc. Chem. Res. 1971, 4, 1.

(72) Zhu, S. J.; Song, Y. B.; Zhao, X. H.; Shao, J. R.; Zhang, J. H.; Yang, B. Nano Res. 2015, 8, 355.

(73) Du, Y. Q.; Yan, H. X.; Huang, W.; Chai, F.; Niu, S. ACS Sustain. Chem. Eng. 2017, 5, 6139.

(74) Yang, L. G.; Wang, L. Z.; Cui, C. F.; Lei, J. Y.; Zhang, J. L. Chem. Commun. 2016, 52, 6154. 
(75) Zhang, H. K.; Zheng, X. Y.; Xie, N.; He, Z. K.; Tiu, J. K.; Leung, N. L. C.; Niu, Y. L.; Huang, X. H.; Wong, K. S.; Kwok, R. T. K.; Sung, H. H. Y.; Williams, I. D.; Qin, A. J.; Lam, J. W. Y.; Tang, B. Z. J. Am. Chem. Soc. 2017, 139, 16264.

(76) Yan, J. J.; Wang, Z. K.; Lin, X. S.; Hong, C. Y.; Liang, H. J.; Pan, C. Y.; You, Y. Z. Adv. Mater. 2012, 24, 5617.

(77) Tsujimoto, H.; Ha, D. G.; Markopoulos, G.; Chae, H. S.; Baldo, M. A.; Swager, T. M. J. Am. Chem. Soc. 2017, 139, 4894.

(78) Zhu, Q. H.; Huang, L.; Chen, Z. P.; Zheng, S. C.; Lv, L. Y.; Zhu, Z. B.; Cao, D. R.; Jiang, H. F.; Liu, S. W. Chem. Eur. J. 2013, 19, 1268.

(79) Viglianti, L.; Leung, N. L. C.; Xie, N.; Gu, X. G.; Sung, H. H. Y.; Miao, Q.; Williams, I. D.; Licandro, E.; Tang, B. Z. Chem. Sci. 2017, 8, 2629.

(80) Situ, B.; Chen, S. J.; Zhao, E. G.; Leung, C. W. T.; Chen, Y. L.; Hong, Y. N.; Lam, J. W. Y.; Wen, Z. L.; Liu, W.; Zhang, W. Q.; Zheng, L.; Tang, B. Z. Adv. Funct. Mater. 2016, 26, 7132.

(81) He, B. Z.; Su, H. F.; Bai, T. W.; Wu, Y. W.; Li, S. W.; Gao, M.; Hu, R. R.; Zhao, Z. J.; Qin, A. J.; Ling, J.; Tang, B. Z. J. Am. Chem. Soc. 2017, 139, 5437.
(82) Lee, J. H.; Twomey, M.; Machado, C.; Gomez, G.; Doshi, M. Gesquiere, A. J.; Moon, J. H. Macromol. Biosci. 2013, 13, 913.

(83) Li, Y.; Kroger, M.; Liu, W. K. Biomaterials 2014, 35, 8467.

(84) Salatin, S.; Khosroushahi, A. Y. J. Cell. Mol. Med. 2017, 21, 1668.

(85) Luzio, J. P.; Rous, B. A.; Bright, N. A.; Pryor, P. R.; Mullock, B. M.; Piper, R. C. J. Cell Sci. 2000, 113, 1515.

(86) Higashihara, T.; Ueda, M. Macromolecules 2015, 48, 1915.

(87) Mark, J. E. Polymer Data Handbook; Oxford University Press: New York, 2009.

(88) Chan, C. Y. K.; Lam, J. W. Y.; Deng, C. M.; Chen, X. J.; Wong, K. S.; Tang, B. Macromolecules 2015, 48, 1038.

(89) Qiu, Z. J.; Han, T.; Kwok, R. T. K.; Lam, J. W. Y.; Tang, B. Z. Macromolecules 2016, 49, 8888.

(90) Hu, R.; Leung, N. L. C.; Tang, B. Z. Chem. Soc. Rev. 2014, 43, 4494.

For Table of Contents Only

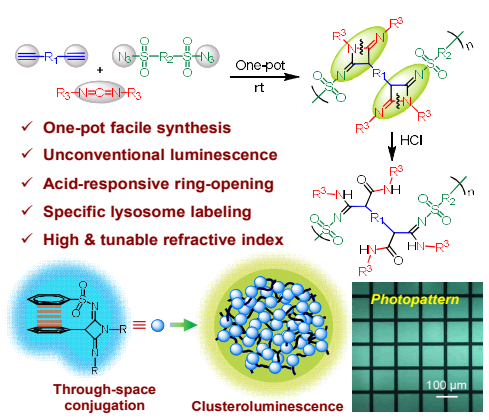

